Научная статья

УДК 930.85

DOI: $10.18101 / 1994-0866-2021-1-3-10$

\title{
ИСТОРИЧЕСКИЕ ЦИКЛЫ В РОССИЙСКОЙ СОЦИОДИНАМИКЕ: ИСТОРИОСОФСКИЙ АНАЛИЗ
}

(C) Сулимин Александр Николаевич

кандидат политических наук, доцент, доцент кафедры истории государства, права и международных отношений, Поволжский институт управления имени П. А. Столыпина — филиал РАНХиГС при Президенте РФ

Россия, 410012, г. Саратов, ул. Московская, д. 164, в/г № 2

kratos84@yandex.ru

Аннотация. В данной статье рассматриваются циклически-волновые закономерности развития государства и общества в социодинамике России. Автор обращает внимание на концептуальные подходы, существовавшие в российской историософской мысли, раскрывающие природу, длительность и прогностический потенциал циклов, волн и ритмов в общественном развитии России.

Отмечается, что в конце XX в. в социальных науках широкое распространение получили европоцентристские подходы к модернизации российского общества, согласно которым Россия в своем поступательном развитии призвана догонять западные страны.

В конце статьи предлагается нелинейная трактовка российской социодинамики через призму смены политических порядков в истории России. Данная концепция призвана отбросить теории зависимости от Запада и обратить внимание на самоподобную логику развития российского исторического процесса.

Ключевые слова: историософия; социодинамика; цикличность; модернизация; энтропия; синергетика; политический порядок.

\section{Для цитирования}

Сулимин А. Н. Исторические циклы в российской социодинамике: историософский анализ // Вестник Бурятского государственного университета. Философия. 2021. Вып. 1. С. 3-10.

Исторический процесс представляет собой богатую эмпирическую основу для исследования циклически-волновых тенденций в российской социальной динамике. В социальных и гуманитарных науках существуют многочисленные концепции социодинамики России, выделяются различные ритмы и циклы состояний российского государства на длительном временном промежутке. При этом для построения спектрального ряда циклов исследователи применяли различную методологию и различные концептуальные подходы к прогнозированию социальных процессов.

Одним из первых фундаментальных исследований, посвященных вопросам цикличности российского общества, стали работы В. Мошкова. Согласно его ме- 
тодологии все страны и народы проходят одни и те же циклы, только в разной временной последовательности [1].

В своей концепции цикличности В. Мошков выделяет фазы подъема и упадка. Фаза упадка характеризуется делегитимизацией власти, расколом общества, формированием партий, бунтами, революционными событиями, а также загниванием господствующей социальной группы (правящей элиты). Что касается основных особенностей фазы подъема, автор отмечает, что он «характеризуется отходом от междоусобий, бунтов, восстаний и революции в область преданий, так как человек подъема миролюбив и не стремится к власти» [2, с. 283-284]. При этом экономический подъем, опора на национальные традиции, повышенное исполнение долга чиновников перед обществом и в целом открытость власти перед обществом становятся важной основой расцвета общества и государства.

Согласно теории В. Мошкова, на цикличность развития общества оказывают влияние уровень консолидации социума по отношению к общепризнанным ценностям, уровень олигархизации господствующих социальных групп, а также степень легитимности власти, что определяет социальную динамику. В. Мошков ничего не пишет о причинах упадков и подъемов в циклах российского общества, ограничиваясь лишь эмпирическими наблюдениями и их экстраполяцией на российский исторический процесс.

Следующим ученым, изучающим ритмы российского общества, стал А. Чижевский. Он первым исследовал воздействие солнечной активности на социальную и политическую активность населения, уверяя, что больше всего крестьянских восстаний, крестовых походов, переворотов, военной активности, революций происходит в максимумах 11-летних циклов солнечной активности. Затем последователи А. Чижевского пытались сопоставить максимумы солнечной активности и политические события в XX в. Согласно концепции А. Чижевского эпохи максимумов циклов продолжаются обычно год-полтора: «1907 — максимум 14-го цикла - всплеск революционного движения в России; 1917 - максимум 15-го цикла - две революции в России; 1928 - максимум 1-го цикла начало индустриализации в СССР по решению XV съезда ВКП(б); 1937 — максимум 17-го цикла - обострение сталинских репрессий; 1947 - максимум 18-го цикла - обострение политической ситуации в СССР, начало кампании против «безродных космополитов»; 1957 - максимум 19-го цикла (самого мощного в истории) - хрущевские реформы, восстание в Венгрии (1956), подавление его советскими войсками. В мире - подъем национально-освободительного движения в Африке; 1968 - максимум 20-го цикла — конец оттепели, бархатная революция в Чехословакии, подавление ее советскими войсками; 1979 - максимум 21-го цикла - ввод советских войск в Афганистан, события в Польше, исламская революция в Иране; 1989 - максимум 22-го цикла - работа І Съезда народных депутатов СССР, активное реформирование СССР, антикоммунистические перевороты в Восточной Европе; 2000 - максимум 23-го цикла - чеченская война; 2013 - максимум 24-го цикла — не известно, что будет» [3].

Таким образом, А. Чижевский пытался доказать, что солнечная активность оказывает влияние на социально-политические катаклизмы, которые происходи- 
ли в России в разное время. Однако, по нашему мнению, влияние солнца не стоит рассматривать как главную причину революционных потрясений, катализатор социальной динамики российского общества. Скорее солнечная активность может служить одним из фактором, влияющим на социально-политический процесс.

Свою методологию и структуру циклов предлагает А. С. Ахиезер [4]. Основным двигателем цикличности российского общества он определяет культурный конфликт и раскол внутри общества. С самого начала истории Российского государства происходит борьба между соборными и авторитарными началами российской политической культуры. Россия стремилась стать более развитым обществом, и что-то в нем изменялось, но традиционная политическая культура тормозила распространение модернизма.

Основная особенность концепции Ахиезера заключается в том, что он рассматривает развитие российского общества через призму европоцентристского подхода. Для него российская цикличность является неким отклонением от нормальности, девиацией. При этом внедрение в российский социум элементов западной политической культуры является торжеством прогресса человеческого общества.

Рассмотрение анализа социальной динамики России через призму западной политической культуры и идеологии, по крайней мере начиная с теории А. С. Ахиезера, стало одной из традиций в российской социальной науке. После распада СССР многие исследователи попытались обосновать причину вступления советского общества на путь демократического строительства как проявление естественного мирового демократического цикла в российской истории. С другой стороны, возникали проблемы демократического транзита, и феномен «партии власти» обосновывался как возрождение авторитарной фазы в российской цикличности [5]. Так появилась концепция «двух культур» - авторитарной и демократической. Современные политические представления зачастую экстраполировались на разные эпохи, без учета исторической специфики. Например, Иван Грозный относился к апологетам автократии, а Петр Первый - демократии. Тем не менее, если следовать принципу историзма, то до определенного времени ни один из этих исторических деятелей не был связан ни с борьбой за «демократию», ни с ущемлением прав и свобод человека, так как этих понятий в то время не существовало.

В связи с неудачным опытом строительства демократии в 1990-х гг. в постсоветской России ряд исследователей попытался доказать, почему социальнополитические новации с Запада не всегда удачно приживаются в российской социальной среде, провоцируя откат к авторитаризму. В. И. Пантин, изучив политические циклы в истории России, показывает, что волны либерализации и модернизации регулярно сменялись волнами антилиберальной контрмодернизации, реформы - контрреформами, ориентация на демократический Запад сменялась ориентаций на авторитарные традиции с Востока и построение «железного занавеса» [6, с. 42]. Автор утверждает, что главной внутренней причиной чередующихся волн реформ и контрреформ выступает раскол культуры, идеологии, общественно-политического уклада жизни на два главных тренда: радикальный 
«либерализм», который защищает права и свободы человека, но игнорирует социальную политику государства, и радикальный «государственный патернализм» (государственный социализм), ущемляющий экономические, политические права и свободы населения, препятствующий вызреванию гражданского общества.

Также В. И. Пантин выделяет 36-летние циклы социально-политического развития России. Ученый полагает, что 36-летний сверхритм - это своего рода главный цикл усложнения и развития российского общества. Выделяя числовой ряд: 1881-1917; 1917-1953; 1953-1989; 1989-2025(7) гг., он отмечает, что каждая из критических дат: 1881, 1917, 1953, 1989 приводила к глубокому экономическому и политическому кризису прежней модели развития, за которой следует ее смена [6, с. 333-393].

Таким образом, ряд российских ученых следует идеям теории модернизации, считая, что на вызов развитого Запада традиционное российское общество отвечало современным же ответом. Однако измерение характера российской социальной динамики европоцентристскими инструментариями не позволяет раскрыть природу нашей социальной среды. Либерализм и консерватизм являют собой разные идейные сущности в России и в европейских странах. Также не стоит забывать, что данные понятия имели различный смысл на самом Западе в разное время. Современные либеральные и консервативные циклы демонстрируют стабильную работу американской и английской социально-политической систем и не могут быть в полной мере использованы для анализа российской социальной динамики.

Отталкиваясь от популярной схемы «модернизация-контрмодернизация», В. Б. Пастухов обращает внимание на существование в российской социальной динамике циклов русской идеологии, выделяя при этом циклы православия, коммунизма и либерализма. По мнению ученого, в России идеология всегда заимствовалась на Западе. Каждый из указанных циклов состоит их четырех фаз функционирования заимствованных идей: импорт, адаптация, ритуализация, деградация. На первой фазе происходит заимствование подходящей идеи с Запада. При этом государство слабо и готово принять новую идею для консолидации общества, которую оно готово принять. На второй фазе западная концепция адаптируется под русские условия и превращается в «русскую идею». Сохраняя свою исходную форму на русской почве, идеология изменяет свое внутреннее содержание. Идеология «огосударствляется» и начинает выполнять специфические русские функции. На третьей фазе западный элемент в идеологии превращается в пустую формальность. Окрепшее государство присваивает «русскую идею» в качестве инструмента манипуляции массового сознания общества. На завершающей четвертой стадии происходит вырождение старой идейной оболочки, которая распадается и теряет свою привлекательность и практическую ценность в массовом сознании общества. Государство, теряя контроль над обществом, начинает вырабатывать новые идеи, способные стать новой объединяющей силой [7]. 
Стоит заметить, что концепция циклов русской идеологии В. Б. Пастухова представляет собой достаточно оригинальную теорию, прослеживающую определенные тренды и изменения в идеологическом обеспечении российского исторического процесса, однако анализирует государственный порядок в социальной динамике России в фокусе торжества государственного произвола, не обосновывая причины этого феномена и его роль в сохранении общества.

Цикличность исторического процесса России анализируется также с точки зрения теории смены властных элит. В. Пашинский считает, что каждые 32 года в России происходил процесс смены поколений власти. Автор обращает внимание на то, что модернизационные реформы правителей зачастую разрушали сложившиеся устои и активно внедряли инновации в течение 32 лет. Затем наступали периоды «десоциализации и административного структурирования, монолитизации и рассредоточения полномочий, образуя единый 65 -летний цикл» $[8$, c. 114-115].

Историк А. Н. Пархоменко считает, что российские циклы воспроизводятся каждые 375,5 года в период катастрофических событий. За точку отсчета цикличности он берет начало правления династии Рюриковичей и затем, прибавляя по 375,5 лет, в результате получает следующие значимые даты: 1238, 1613, 1989 и 2365. Каждой из трех первых дат соответствуют трагические события: нашествие ордынцев, династический кризис и распад СССР. А. Н. Пархоменко отмечает, что в структуре его циклов имеются определенные закономерности: «Между 17-м и 32-м годами циклов возникают "правители централизаторы", а в 83-90 годах цикла к власти приходят "воплотители", при которых формируются основы государственности, затем в 295-304 годы цикла появляется "правительбунтарь", примечая новую социальную базу власти» [9, с. 11-12]. Например, А. Боголюбский примечает боярство, которое потом приводит к власти князьвоплотитель И. Калита. Иван Грозный приметил дворян, на которых опирался царь-воплотитель Петр Первый, и наконец В. И. Ленин приметил номенклатуру, на которую впоследствии опирался вождь-воплотитель И. В. Сталин. В результате в каждом цикле формируется новый элитный слой Российского государства.

Исследуя российскую социальную динамику через череду смен российских государственных образований, Ф. Синельников обращается к теме цикличности российских держав. Основываясь на некоторых верифицируемых критериях российской державности (контролируемая территория, демографическое состояние, состояние вооруженных сил, идеологическое оформление власти, политическая элита и стиль ее правления), автор пытается определить внутреннюю логику процессов развития и деградации российского общества. В историческом процессе России Ф. Синельников выделяет три ключевые державы. Первая держава возникает в результате монгольского нашествия и существует от Александра Невского до периода междуцарствия 1610-1613 гг. Эпоха Второй державы связана с правлением династии Романовых. Третья держава зарождается в результате революционных событий 1917 г. и существует до сих пор.

По мнению Ф. Синельникова, заметные в 1612-1613 гг., в феврале 1917 г. и августе 1991 г. проявления предельного ослабления российского государства по- 
лучили разное разрешение. Если в первых двух случаях ослабленная держава гибнет, уступая место новой, то в 1991 г. гибели державы не произошло, но ее деградация продолжилась. Делая вывод, что в современном российском государстве находит свое выражение деградация Третьей державы, автор указывает на неизбежность новой «Перестройки» [10].

Концепция социальной динамики российских держав Ф. Синельникова в отличие от других теорий базируется на принципе эмерджентности, широко применяющемся в теории систем, по которому российская государственность развивается по собственной логике развития, без какого-либо влияния модернизационных волн извне.

В последние годы в изучении исторических процессов активно используется методологический аппарат точных наук. Например, В. Г. Будановым применяется синергетическая методология для анализа ритмокаскадных закономерностей в исторической динамике России. Ученый в своих трудах пытается совместить нелинейную методологию с социокультурной динамикой и выдвигает гипотезу о существовании социально-исторических архетипов, которые включены в ритмокаскадную цепь развития [11].

По мнению В. Г. Буданова, исторически значимые этапы и события за 400 лет укладываются на сеть из девяти ритмокаскадных деревьев, задающих своеобразную архетипическую систему координат. В целом концептуальный аппарат В. Г. Буданова, применяя методы математического моделирования, предлагает оригинальную трактовку ритмокаскадов в истории России, позволяющую прогнозировать возможные социально-политические изменения в будущем.

Анализ теорий цикличности российского общества через призму историософских концепций показывает достаточно вариативный характер идентификации структуры циклов. Существует множество критериев для выявления природы цикличности российского общества. Ряд исследователей замечает, что в основе циклов, ритмов и волн в российской истории лежат кризисы и катастрофы, разделяющие различные эпохи и меняющие логику развития государства и социума. Другие исследователи берут за основу теорию политической модернизации, уподобляющую природу российских циклов тенденциям развития политических систем западных стран, а сторонники мирсистемного подхода И. Валлерстайн, Дж. Арриги рассматривают Россию в контексте развития трендов мировой капиталистической системы.

Синергетический подход позволяет рассмотреть развитие любой социальной системы с точки зрения собственной логики развития общества, обращая внимание не только на кризисы, катастрофы и революции, но и на устойчивые трансисторические структуры, позволяющие обществу выжить в тех или иных условиях, под воздействием различных разрушительных тенденций извне.

Наша концепция опирается на нелинейную методологию изучения социальных процессов и обращает внимание на то, что в российском обществе на протяжении всей его истории воспроизводился политический порядок, представляющий собой образцы высших социально-политических идей, определяющие направленность развития и организацию социальных институтов на долгосроч- 
ную перспективу [12]. Представляя политический порядок в качестве низкоэнтропийного состояния российского социума, нами выделяются четыре пространственно-временных структуры его политической организации в историческом процессе: древнерусский порядок, московский порядок, петербургский порядок, советский порядок. При этом российский исторический процесс характеризуется нелинейными тенденциями, когда фазы самоорганизации политического порядка с переходом на режим низкой энтропии сменялись хаотическими периодами высокой энтропии, «размывающими» параметры порядка социума, и наоборот. Политические циклы при этом содержали три фазы динамики политических изменений: 1) фаза самоорганизации политического порядка; 2) фаза организации политического порядка, 3) фаза дезорганизации политического порядка.

После распада СССР российское общество из состояния дезорганизации советского порядка постепенно переходит в стадию формирования нового современного порядка. Изучение данного процесса требует дальнейшего анализа соотношений тенденций самоорганизации и организации, упорядоченности и хаоса, влияния внешней социально-экономической и политической среды на внутренние процессы.

\section{Литература}

1. Мошков В. А. Новая теория происхождения человека и его вырождения, составленная по данным зоологии, геологии, археологии, антропологии, этнографии, истории и статистики. Варшава: Тип. Губ. правл., 1907. Т. 1. 239 с.

2. Азроянц Э. А. Глобализация: катастрофа или развитие? Современные тенденции мирового развития и политические амбиции. М.: Новый век, 2002. С. 283-284.

3. Лупачев Ю. В. Историометрические циклы А. Л. Чижевского: реальность и прогностические возможности // Вестник Российской академии наук. 1996. Т. 66, № 9. C. 796-799.

4. Ахиезер А. С. Россия: критика исторического опыта (Социокультурная динамика России). Т. І. От прошлого к будущему. Новосибирск: Сибирский хронограф, 1998. 804 с.

5. Petro N. N. The Rebirth of Russian Democracy: an Interpretation of Political Culture. Cambridge, Mass: Harvard University Press, 1995. 225 p.

6. Пантин В. И., Лапкин В. В. Философия исторического прогнозирования: ритмы истории и перспективы мирового развития в первой половине XXI века. Дубна: Феникс+, 2006. $448 \mathrm{c}$.

7. Пастухов В. Б. Конец русской идеологии (Новый курс, или новый путь) // Политические исследования. 2001. № 4. С. 55-62.

8. Пашинский В. М. Цикличность в истории России (Взгляд с позиций социальной экологии) // Политические исследования. 1994. № 4. С. 111-115.

9. Пархоменко А. Н. Циклы российской действительности (исторический сценарий). М.: Перо, 2013. $650 \mathrm{c}$.

10. Синельников Ф. Циклы российского великодержавия и современность // Переход. 2011. № 1. URL: http://perehodjournal.ru (дата обращения: 04.01.2021). Текст: электронный.

11. Буданов В. Г. Ритмокаскады истории и прогноз развития социальнопсихологических архетипов России до 2050 г. // Синергетическая парадигма. Социальная синергетика. М.: Прогресс-Традиция, 2009. С. 234-264. 
12. Сулимин А. Н. Нелинейная динамика российских политических порядков сквозь призму исторического процесса // Genesis: исторические исследования. 2015. № 5. C. $338-364$.

Статья поступила в редакиию 15.01.2021; одобрена после рецензирования 25.01.2021; принята к публикации 09.02.2021.

\section{HISTORICAL CYCLES IN RUSSIAN SOCIODYNAMICS: A HISTORIOSOPHICAL ANALYSIS}

\section{Aleksandr N. Sulimin}

Cand. Sci. (Polit.), A/Prof.,

Stolypin Povolzhsky Institute of Management — Branch of the Russian Presidential Academy of National Economy and Public Administration

164 Moskovskaya St., Saratov 410012, Russia

kratos84@yandex.ru

Abstract. The article discusses the cyclic-wave patterns of the development of the state and society in Russian sociodynamics. We draw attention to the conceptual approaches of the Russian historiosophical thought, which reveal the nature, duration and prognostic potential of cycles, waves and rhythms in the social development of Russia.

It is noted that at the end of the $20^{\text {th }}$ century, Eurocentric approaches to the modernization of Russian society were widely used in social sciences, according to which Russia in its progressive development is designed to catch up with Western countries.

In conclusion, we have proposed a non-linear interpretation of Russian sociodynamics through the prism of changing political orders in the Russian historical process. This concept is designed to discard the theory of dependence on the West and pay attention to the self-similar logic of the development of the Russian historical process.

Keywords: historiosophy; sociodynamics; cyclicity; modernization; entropy; synergetics; political order.

For citation

Sulimin A. N. Historical Cycles in Russian Sociodynamics: A Historiosophical Analysis. Bulletin of Buryat State University. Philisophy. 2021; 1: 3-10 (In Russ.).

The article was submitted 15.01.2021; approved after reviewing 25.01.2021; accepted for publication 09.02.2021. 